\title{
Administration of Microencapsulated Enterococcus Faecium ABRIINW.N7 With Fructo- Oligosaccharides and Fenugreeko the Mortality of Tilapia Challenged with Streptococcus Agalactiae
}

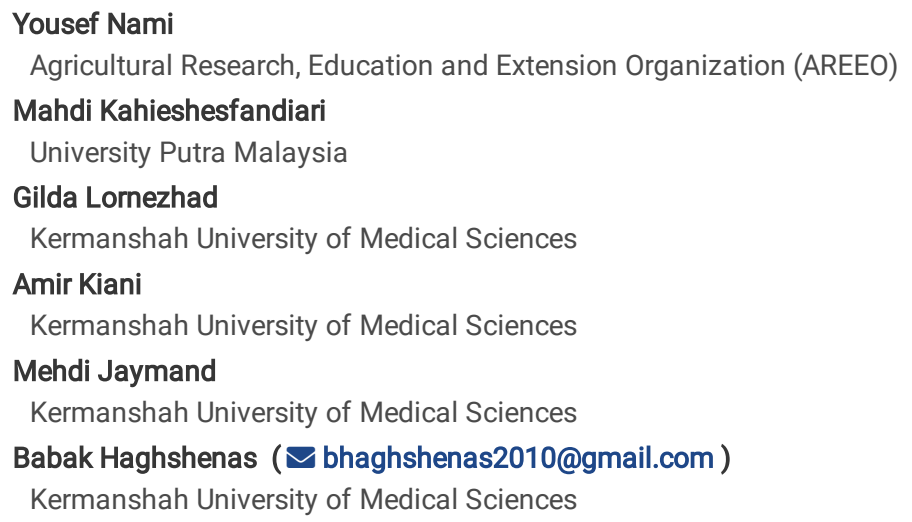




\section{Abstract}

The aim of study was to examine the probiotic potential of a microencapsulated E. faecium ABRIINW.N7 in the control of Streptococcus agalactiae infection in hybrid (Oreochromis niloticus $\times$ Oreochromis mossambicus) red tilapia. A two-phase experiment approach was completed in which E. faecium bacteria were propagated, from which a culture was isolated, identified using molecular techniques, and microencapsulated to produce a stable commercial fructo-oligosaccharides (FOS) and fenugreek (Fk) product of optimal concentration. This FOS and Fk product was assessed in a 12-week in vivo challenge study completed, in which red hybrid tilapia were allocated to one of five treatments: No Streptococcus agalactiae (Sa) challenge (G01) (CON); Sa challenge only (G02) $\left(\mathrm{CON}^{+}\right)$; Sa challenge in a free cell (Free Cell) G03; Sa challenge with 2\% (w/v) Alginate (G04); Microencapsulated FOS and Fk (G05-G011). In vitro results showed a high encapsulation efficiency and acceptable viability of probiotic bacteria within the simulated fish digestive system and high stability of viable cells in all gel formulations. In vivo challenges demonstrated that the G05-G011 FOS and Fk product could be used to control tilapia fish infected with $S$. agalactiae and represented a novel investigation using microencapsulation E. faecium as a probiotic diet tilapia fish to control S. agalactiae and lower fish mortality. It is recommended that local herbal gums such as PG and Fk in combination with ALG can be used as a suitable scaffold and an ideal matrix for the encapsulation of probiotics. These herbal gums as prebiotic also promote the growth of probiotic cells in the food environment and digestive tract.

\section{Introduction}

In recent years, tilapia fish has become one of the most popular species to produce human food, due to it being a remarkable source of protein and source of essential vitamin and minerals. The traditional aquaculture of tilapia has shown that it has become an important food commodity and received considerable scholarly attention in recent years, mainly due to significant short reproductive cycle, rapid growth, high resistance to most common diseases, stress, changes in environmental temperature and poor water quality, while having relatively low feed requirements and being feed efficient, which lowers feed costs ${ }^{1}$. The literature review demonstrates that nearly more than one hundred species was recognized in the worldwide, which include a log traditional or ornamental fish of economic importance along with food species of which the hybrid (Oreochromis niloticus $\times$ Oreochromis mossambicus) red tilapia is particularly appealing, due to the resemblance they show to other popular species ${ }^{2}$.

Some of the major challenges in the intensive farming of tilapia include high operating costs that involve labour, feed, energy and disease control ${ }^{3}$. Pervious literature has reported that protozoa, metazoan, crustaceans, bacteria, mycotic and viral pathogenic factors can be the cause of significant amounts of mortality in the tilapia aquaculture industry and disease threatens are increasing and result in severe financial losses due to high mortality rates ${ }^{4}$. Streptococcal bacteria are a well-known pathogen of cultivated and wild tilapia stocks that are predominantly facultative anaerobes, which have been separated into non-spore forming gram-positive cocci and gram-negative according to cytochrome enzymes, which are arranged in pairs and chains. The genera of Streptococcaceae bacteria has several species such as Streptococcus iniae, Streptococcus shiloi and Streptococcus agalactiae commonly found in hot climates and is a major cause of septicemia and meningoencephalitis in many species of maritime and freshwater fish, which has been highlighted as one of the main obstacles on tilapia farming worldwide ${ }^{5}$. S. agalactiae can be responsible for 50 to $75 \%$ and sometimes up to $100 \%$ of mortality in a wide range of fish 6 .

Meningitis is the most typical clinical characteristic manifested in tilapia infected by $S$. agalactiae and fish that survive a $S$. agalactiae infection show neurological disorders, such as constant and aberrant swimming, exophthalmia and corneal opacity, and pathological changes in meningeal congestion and granulocyte infiltration. However, the mechanism of damage to the central nervous system in tilapia caused by $S$. agalactiae remains unclear.

There are a number of prevention and control strategies for marine infectious diseases, which include vaccination, antibiotic treatment antimicrobial compounds dietary supplements, probiotics prebiotics, nonspecific immunostimulants immune stimulating functional feeds, medicinal plant products, the use of genetically resistant stock and transgenic fish, water disinfection, biological control and control of animal movement are the best approaches in control of infectious diseases of fish. Due to the need to lower antimicrobial resistance, one of the best ways to minimize the occurrence of major infectious diseases in tilapia is the oral supplementation of probiotics. In order to commercialize such functional foods the probiotic cells must exhibit a high resistance to the enzymatic conditions of fish digestion as well as acceptable stability under differing conditions of heating and humidity. These goals can be achieved by controlled release through the microencapsulation of probiotics, using appropriate protective methods and matrixing materials ${ }^{7}$. Probiotics have been considered as useful enhancers for growth performance, health and survival of aquatic animals. Main sources for obtaining appropriate probiotics in aquaculture are skin, gills, mucus of aquatic animals, environments or commercial products and culture collections ${ }^{8}$. Although bacteria are able to be pathogen to an aquatic species, it can be advantageous to another species. Using probiotics in aquaculture can be as a mono or multiple species, or associated with prebiotics, immunostimulants, in live or dead forms. Some advantages of probiotics in aquaculture: a) they can modify the surrounding microbial community or host associated ones. b) Enhancement of feed or nutritional value. c) Improving immune response of aquatic animals against infections and diseases ${ }^{9}$. Enterococci are known to be ubiquitous microorganisms, opportunistic pathogens and lactic acid bacteria (LAB) normal inhabitants of the gastrointestinal tract of man and animals. These bacteria are ubiquitous in nature and have been employed in the food industry as probiotics ${ }^{10}$. Recently, Enterococci showed remarkable bacteriocins activity that has been suggested as a new probiotic trait when selecting beneficial microbes. Enterococci are increasingly as potential probiotic candidates and several Enterococcus strains have been described as producing antimicrobial compounds, including bacteriocins.

The greatest beneficial effects of probiotics are achieved when they survive through the gastrointestinal tract and remain bioactive at their target site. Nevertheless, several probiotics are incapable of delivering their targeted beneficial effect of the host for many reasons; adverse conditions such as high temperature, high humidity, and drying may elicit a sub-lethal effect on microorganisms. Herbal-based hydrogels such as Persian Gum (PG) are low cost, 
novel, and can form microencapsulated beads with high durability by ion exchange with a negatively charged ALG structure ${ }^{11}$. While PG is secreted from mountain almond (Amygdalus scoparia Spach) (synonymous: Prunus scoparia Spach) trees and forms a hydrogel in it natural physiological condition, which is a polysaccharide that is composed of galactose, $(1 \rightarrow 3) \beta-D-$ Galp, and rhamnose. The therapeutic effect of PG is known as a herbal medicine for swelling of the joints, toothache, and coughs. Therefore, if appropriately tailored to poly (AAm) using N, N-MBAAm and ammonium persulfate (APS), it could be considered a superior candidate for the microencapsulation ${ }^{8}$. ALG is the most commonly utilized coating material used for probiotic encapsulation. However, ALG has disadvantages such as high porosity and susceptibility to low acidic conditions ${ }^{9,10}$. The small-scale extrusion method is easy to use, low-cost, and simple compared to other encapsulation methods.

The overall goal of this work was to probiotic properties and half-life estimation of microencapsulated E. faecium by alginate - Persian gum microcapsules against $S$. agalactiae in challenged red hybrid tilapia fish. Therefore in this study, alginate-PG blend with various concentrations of FOS and fenugreek were extruded to produce E. faecium microencapsulated beads for being added to the aquaculture products such as food pellets. Moreover, the morphological characteristics, encapsulation efficiency, anti- pathogenicity, probiotic cell viability under tilapia digestive conditions and during storage time were investigated. This research is the novel investigation to use microencapsulated $E$. faecium probiotic-supplemented diet to control mortality rate of infected S. agalactiae tilapia fish.

\section{Materials And Methods}

All protocols and animal experiments in this study were approved by the Committee on the Ethics of Animal Experiments of Kermanshah University of Medical Sciences, Iran (Approval ID: IR.KUMS.REC.1399.531), and performed in compliance with the guidelines and regulations from Kermanshah University of Medical Sciences of Iran (https://ethics.research.ac.ir/docs/pages/Guideline-Res.pdf) and the ARRIVE guidelines for involvement of animals (fish).

This study was completed in a two-phase experiment that included (phase 1) an in-vitro study in which bacteria were cultured and an isolate was prepared and identified using molecular techniques. This isolate was used to prepare a stabilized probiotic that was included at an optimal concentration using an in vitro assay to prepare commercial fructo-oligosaccharides (FOS) and Fk by routine microencapsulation. The efficacy of this was assessed in a 12-week in vivo feeding study (phase 2).

\subsection{Phase 1: In vitro assay}

\subsubsection{Media and materials}

The S. agalactiae was obtained from University Putra Malaysia (UPM) (Malaysia). The Persian gum (PG) and Fk were procured locally (Iran). Sodium hydrogen phosphate, hydrochloric acid, calcium chloride, sodium hydroxide, MRS broth, MRS agar, and Acrylamide (AAm) (Merck, Germany) and N, Nmethylene bis-acrylamide (NN-MBAAm), ammonium persulphate (APS), fructooligosaccharides (FOS), oxgall, and sodium ALG were prepared (SigmaAldrich, Germany).

\subsubsection{Molecular identification and strain characterization of E. faecium}

The E. faecium strain was isolated from ewe colostrum and grown and amplified on MRS broth medium for $48 \mathrm{~h}$ at $37^{\circ} \mathrm{C}$. The genomic DNA was extracted based on methodology described by ${ }^{11}$ and following genomic DNA extraction, the amplification of 16S-rRNA gene was carried out by the primers ( $F 5^{1}$ AGAGTTTGATCCTGGCTCAG-3') and R 5'-GGCTGCTGGCACGTAGTTAG-3'). The amplification was performed with a $25 \mu \mathrm{L}$ final volume containing 0.4 $\mu \mathrm{mol} / \mathrm{L}$ primers, $40 \mathrm{ng}$ of chromosomal DNA, and master mix (Ampliqon, Herlev, Denmark). The amplification reaction was completed following thermocycle program: four min at $96^{\circ} \mathrm{C}$ as an initial denaturation; $30 \mathrm{sec}$ at $96^{\circ} \mathrm{C}$ as denaturation for $30 \mathrm{cycles} ; 30 \mathrm{sec}$ at $48^{\circ} \mathrm{C}$ as annealing and $45 \mathrm{sec}$ at $72^{\circ} \mathrm{C}$ as the first extension, with a final extension of $4 \mathrm{~min}$ at $72^{\circ} \mathrm{C}$. The total volume of reaction was $50 \mu$ l and the PCR product was visualized through $0.8 \%\left(\mathrm{w} / \mathrm{v}\right.$ ) agarose gel electrophoresis ${ }^{12}$. The isolate was identified using RCR product sequencing (Macrogene, Korea) and was blasted in the NCBI and GenBank site (http://blast.ncbi.nlm.nih.gov/Blast.cgi).

A disc diffusion method was used to evaluate probiotic susceptibility against seven high-consumption antibiotics used in aquaculture including oxytetracycline, tetracycline, amoxicillin, ampicillin, erythromycin, sulphonamides, and oxolinic acid. The isolate was completely incubated in MuellerHinton agar plates, and the antibiotic disks were placed on plates with the use of sterilized forceps and then incubated at $37^{\circ} \mathrm{C}$ for 18 to $24 \mathrm{~h}$. The diameter of the clear zones around disks were measured using a digital caliper ${ }^{13,14}$ and the isolated strains were classified as sensitive, intermediate and resistant on the basis of the size of the clear zone (CLSI, 2007). An agar diffusion well method was applied to investigate the antibacterial activity of probiotic cells against the five most relevant pathogens likely to be found in aquatic farms such as Salmonella enterica (ATCC 9115), Streptococcus agalactiae (ATCC 13813), Streptococcus iniae (ATCC 29178), Yersinia ruckeri (PTCC 1888), and Clostridium botulinum (ATCC 3502) were incubated overnight in MRS broth medium at $37^{\circ} \mathrm{C}$ and the isolate was centrifuged for $10 \mathrm{~min}$ at $14,000 \times \mathrm{g}$. The supernatant was filtered by using a $0.2 \mu \mathrm{m}$ filter and $100 \mu \mathrm{L}$ of filtered neutralized supernatant was added to the $7 \mathrm{~mm}$ diameter wells created on an MRS agar plate, which was pre-inoculated with indicator pathogens. The agar plates ( $8 \mathrm{~cm}$ plates) were incubated at $37^{\circ} \mathrm{C}$ overnight and the clear zone that formed indicated a positive antimicrobial activity of isolated metabolites on the pathogens 15,16 . The probiotic susceptibility and resistance was evaluated under a an acidity of $\mathrm{pH} 1.4$ and alkalinity using bile salt ( $0.5 \%$ w/v oxgall) at a $\mathrm{pH}$ of 8 at $37^{\circ} \mathrm{C}$ to mimic the digestive conditions in fish and the culture medium was centrifuged $(6,000 \times \mathrm{g}$ for $3 \mathrm{~min})$. These cell plates were resuspended for $2 \mathrm{~h}$ by a gentle agitation and the survival rates were calculated by the equation described by Haghshenas et al. (2016) ${ }^{15}$.

\subsubsection{Harvesting and inoculation of probiotic cell}


The E. faecium cells were grown and amplified in $200 \mathrm{~mL}$ MRS medium for $18 \mathrm{~h}$, at $37^{\circ} \mathrm{C}$, under anaerobic conditions. The amplified cells were harvested by centrifuging at $18,000 \times \mathrm{g}$ for $20 \mathrm{~min}$, at $4^{\circ} \mathrm{C}$, washed and re-suspended in $10 \mathrm{~mL}$ sterile phosphate buffer saline (PBS, Merck) at a pH of 7.2 . The concentrated probiotic cells were enumerated to a desirable amount in the MRS agar, using the pour plate method, prior to use. Equal amounts of the probiotic cell population was segmented and then incorporated with different biopolymers and prebiotic blends were used in the microencapsulation process.

\subsubsection{Preparation of fenugreek gel powder}

The Fk gel was extracted according to Mandal et al. (2006) ${ }^{21}$, with some modifications, in which $100 \mathrm{~g}$ of ground Fk seeds were soaked in $500 \mathrm{ml}$ of distilled water for $1 \mathrm{~h}$ at a $\mathrm{pH}$ of 8 , at $68^{\circ} \mathrm{C}$ and continuously stirred. A homogenous gel was centrifuged for $30 \mathrm{~min}$ at $12000 \times \mathrm{g}$ to separate the gel phase, which was washed twice with distilled water and applied in microencapsulation matrix after being dried to a powder (by putting in room temperature).

\subsubsection{Purification of Persian gum}

The gel obtained from Persian Gum (PG) was purified according to Simas-Tosin (2009) ${ }^{17}$, with some modifications, in which $30 \mathrm{~g}$ of dry PG was dispersed in $1000 \mathrm{ml}$ of distilled water at $70^{\circ} \mathrm{C}$ and a pH of 8 and was allowed to dissolved slowly over $12 \mathrm{~h}$. The impurities were precipitated by high-speed centrifugation, at $18000 \times \mathrm{g}$ for $20 \mathrm{~min}$, to remove insoluble residues and the purified gel was dried overnight in the oven at $40^{\circ} \mathrm{C}$, followed by which the powder produced was applied in the microencapsulation process according to Simas-Tosin (2009) ${ }^{17}$.

\subsubsection{Microencapsulation of E. faecium}

The E. faecium cells were microencapsulated utilizing a modified extrusion method using ALG-Persian Gum (PG) with various prebiotic (FOS and Fk) concentrations and the un-microencapsulated cells and ALG-encapsulated cells (ALG) were used as the control. The PG gel, sodium ALG, FOS, and Fk were autoclaved $\left(121^{\circ} \mathrm{C}\right.$ for $20 \mathrm{~min}$ ) prior to microencapsulation step, followed by which the $\mathrm{E}$. faecium cells ( $10 \%$ (w/v)) were suspended in five $\mathrm{mL}$ of FOS and Fk $(0,1.0,1.5$ and $2 \%)$ solutions and then mixed with $10 \mathrm{~mL}$ of PG $(0.5 \%(\mathrm{w} / \mathrm{v}))$ and $10 \mathrm{ml}$ of sodium ALG (1.5\% (w/v)) solutions and the final prebiotic concentrations were $0,0.2,0.3$, and $0.4 \%$ respectively. A five $\mathrm{mL}$ sample of the of gel solutions were stirred and mixed for 30 minutes to produce homogeneous mixtures, which were extruded through a 21 gauge nozzle in $300 \mathrm{~mL}$ sterile $\mathrm{CaCl} 2(0.5 \mathrm{M})$ to create the microencapsulated beads. The beads were filtered (using Whatman Paper No. 1) and rinsed twice with sterile water before being used for subsequent experiments and then stored in peptone solution $(0.1 \%(\mathrm{w} / \mathrm{v}))$ at $4^{\circ} \mathrm{C}$ according to Haghshenas et al. (2015) ${ }^{11}$

\subsubsection{Water activity, moisture content, and encapsulation efficiency (EE) of beads}

The water activity of the beads was assessed using a water activity meter (Dewpoint, USA) at a constant temperature of $24 \pm 0.5^{\circ} \mathrm{C}$ and the moisture content of the powdered microencapsulated beads was determined by drying the samples in an oven at $105^{\circ} \mathrm{C}$ for 12 hours ${ }^{18}$. The efficacy of encapsulation was determined using $100 \mathrm{mg}$ of microencapsulated beads that were dissolved in $20 \mathrm{~mL} \mathrm{PBS}$ at a pH of 7.2 , at $37^{\circ} \mathrm{C}$ for 60 min, followed by which the viable cells were serially diluted and counted as CFU per gram on MRS agar using the pour plate technique and calculated according to the following equation:

Encapsulation efficiency $(\mathrm{EE})=(\log 10 \mathrm{M} / \log 10 \mathrm{Mo}) \times 100$

Where $\mathrm{M}$ denotes the number of viable bacteria cells entrapped in the beads and Mo defines the free viable cells before microencapsulation and the data were expressed as the mean of three counts \pm standard deviation ${ }^{19}$.

\subsubsection{Survival rate of E. faecium under fish simulated digestive conditions}

The protective efficacy of beads and the viability of microencapsulated bacteria under fish simulated digestive conditions was evaluated using 100 mg of each blend formulation, which were incubated individually by gentle stirring them at $100 \mathrm{rpm}$ in $20 \mathrm{ml}$ of simulated gastric juices $\left(\mathrm{pH} 1.4\right.$ at $\left.37^{\circ} \mathrm{C}\right)$ and intestinal juice $\left(0.5 \% \mathrm{w} / \mathrm{v}\right.$ oxgall, $\mathrm{pH} 8$ at $\left.37^{\circ} \mathrm{C}\right)$ for $0,30,60,90$ and $120 \mathrm{~min}$, followed by which the beads were disintegrated in $10 \mathrm{~mL}$ PBS (pH 7.2 ) and viable cells were counted by the pour plate technique according to the following calculation:

Survival rate $(\%)=(\log \mathrm{CFU} / \mathrm{g}$ cells after disintegrate/log $\mathrm{CFU} / \mathrm{g}$ cells before disintegrate $) \times 100$

In which CFU displays the number of colony-forming units on MRS agar by the pour plate technique according to Haghshenas et al. (2016) ${ }^{15}$.

\subsubsection{Storage stability of microencapsulated E. faecium in feed pellets}

The storage stability of the microencapsulated and un-microencapsulated probiotic cells was investigated in a grower fish pellet (Dindings, Malayan Flour Mills, Berhad, Malaysia) over an 8 week storage period, with the cell viability being measured weekly at $0,7,14,21,28,35,42,49$ and $56 \mathrm{~d}$ of storage at $25^{\circ} \mathrm{C}$. The stability assay was completed using $5 \mathrm{~g}$ feed pellets that contained $500 \mathrm{mg}$ of microencapsulated cells which were dissolved in $50 \mathrm{ml}$ sodium citrate solution $(50 \mathrm{mM})$ at room temperature and then gently stirred at $100 \mathrm{rpm}$ and a pH of 8 . The cells released were serially diluted 10 times using a saline solution, followed by which $20 \mu \mathrm{l}$ of the diluted solution was used to calculate the viability (\%) of the cells following their anaerobic growth at $37^{\circ} \mathrm{C}$ for $24 \mathrm{~h}$, using the pour plate method according to Haghshenas et al. (2015) 20

\subsubsection{Release assay of microencapsulated E. faecium}

A release assay was completed in the microencapsulated E. faecium, using one gram of each microencapsulated beads, which were placed in $200 \mathrm{ml}$ of simulated fish intestine solution that contained digestive enzymes lipases, proteases, and carbohydrases, which was incubated with gentle stirring at 100 
$\mathrm{rpm}$, at $\mathrm{pH}$ of 8 and temperature of $37^{\circ} \mathrm{C}$. The samples were taken at one-hour intervals for 12 hours and the released probiotic cells were counted using a pour plate method according to Mandal et al. (2006) ${ }^{21}$

\subsection{Phase 2: In vivo challenge study}

\subsubsection{Fish growth conditions}

The fish were bought from a commercial farm located in the research center of University Putra Malaysia (UPM), were weighed (mean $50 \pm$ SD $( \pm 0.55) \mathrm{g}$ ) and were transferred to two tone fiberglass tanks for a two week acclimatization period at the research center of UPM, Puchong, Malaysia. The water was maintained at a pH between 7.2 and 8 , temperature of $27( \pm 2){ }^{\circ} \mathrm{C}$, hardness of 75 to $100 \mathrm{mg} / \mathrm{L}$, dissolved oxygen of 7 to $8 \mathrm{mg} / \mathrm{L}$ and an ammonia concentration of $<0.1 \mathrm{mg} / \mathrm{L}$, which was renewed at an equivalent of $10 \%$ of the water daily in order to remove waste feed and fecal matter.

\subsubsection{Experimental treatments and design}

The 12-week in vivo study was completed in a glass aquarium rearing system; Three hundred thirty healthy fish were divided into glass aquariums, ten fish in each aquarium with three replicates. During which the fish received one of the following diets: (G)-G01 negative control treatment (CON) without $S$. agalactiae challenge; $\mathrm{G} 02$ positive control treatment, (CON+) with S. agalactiae challenge; G03 (Free Cell) with S. agalactiae challenge in a free cell format; G04 (ALG) with S. agalactiae challenge and $2 \%$ (w/v) Alginate; G05-G011 microencapsulated E. faecium probiotic treatment incorporated with fructooligosaccharides (FOS) and Fk. S. agalactiae glycerol stock was sub-cultured onto blood agarFew colonies were sub-cultured into Brain heart infusion broth (BHIB) (Merk, Germany). To enhance the virulence of bacteria, $1 \mathrm{~mL}$ of $S$. agalactiae with high concentration $(109 \mathrm{CFU} / \mathrm{mL})$ was IP injected to red hybrid tilapias. Fish showing signs of streptococcosis were killed to re-isolate the $S$. agalactiae. Then, the confirmed isolates were sub-cultured on blood agar before inoculating into the BHIB. Sixty colonies were sub-cultured into the BHIB. Afterwards, 10 -fold serial dilution and colony counting were utilised to determine the bacterial concentration. This virulent bacterial inoculum was immediately used for challenge. The fish were given an intraperitoneal injected of $0.1 \mathrm{~mL}$ of $S$. agalactiae $\left(1.6 \times 10^{8} \mathrm{CFU} / \mathrm{mL}\right)$ and one group was selected as the control group and injected with $0.1 \mathrm{~mL}$ of PBS. Injection was done by 1 $\mathrm{mL}$ insulin syringe. The aquariums were aerated with freshwater at $27 \pm 2^{\circ} \mathrm{C}$ and armed with top filters to remove faces.

\subsubsection{Anti-pathogenicity against Streptococcus agalactiae and histopathological assay}

The fish were offered feed twice a day at $5 \%$ of the bodyweight of grower pellets containing the different concentrations of probiotic mixtures. Weekly, fishes were anesthetized by adding $0.1 \mathrm{~mL}$ clove oil per lot and their weight was recorded. The weight gain (WG), daily weight gain (DWG), relative growth rate (RGR), percent weight gain (PWG), and specific growth rate (SGR) was calculated but no any significant differences was observed in different groups. At 90 days of this experiment, the fish were screened for any abnormal behavior, clinical signs and survival post-injection and dead fish were assessed for pathogens isolated from the kidney, liver, eye and brain using loops. The samples were cultured on trypticase soy agar (TSA, Merk, Germany) and incubated at $30^{\circ} \mathrm{C}$ for $24 \mathrm{~h}$ to determine whether mortality was caused by Streptococcus species. The histopathological tests were completed on tissue samples collected from the liver, spleen, kidney, brain, and eye from the fish and these were submerged in $10 \%$ formalin for at least $24 \mathrm{~h}$ and placed in the cassette. All the samples of organs and guts were placed in processing machines with different concentrations of ethanol and melted paraffin for dehydration and infiltration of tissues. Then, the tissues were embedded into paraffin blocks and allowed to freeze. Afterwards, the samples were sectioned with a Jung Multicut microtome (Leica, Germany) and located on the slides. Finally, the slides were subjected to routine Harris' Hematoxylin and Eosin (H\&E) staining and then the organs slides viewed under a microscope (Olympus, Japan). The survival rate was revealed according to the following formula 22.

Survival Rate $(\%)=$ (number of live fish at the end of test) / (number of live fish at the beginning of test) X 100

\subsection{Statistical analysis}

The data was assessed for normality of distribution and found to be normally distributed. The experiments were treated as completely randomized design with three replications for each experimental group. The data were then analyzed using ANOVA (SPSS software) and Duncan test and means with $P<0.05$ was considered as the significant differences.

\section{Results And Discussion}

\subsection{Molecular identification and strain characterization of E. faecium}

Once sequencing of the 16S-rRNA PCR-amplified fragment (1500 bp) was completed and its conformity with the sequences deposited in GenBank has been assessed, the strain isolated from the ewe colostrum was identified with 99 to 100\% homology as E. faecium (Accession number: MK367697). In accordance with FAO/WHO guidelines, molecular identification of probiotic strains by 16S-rRNA sequencing (FAO, WHO, 2002) the threshold value for bacterial taxonomic studies was approx. $97 \%$ and based on the results in this study where the 16S-rRNA sequencing with $99-100 \%$ similarity, which was performed as an accurate and validated method according to Deng et al. (2008) ${ }^{23}$.

Probiotic bacteria require specific characteristics to be efficient in improving host health and according to scientific agreements, the evaluation and assessment of the probiotic properties of bacteria should be completed according to standard in vitro experiments, which include the susceptibility to antibiotics, anti-pathogenic activity and resistance to acid and bile in the digestive tract ${ }^{24}$. In this study, the E. faecium showed appropriate antibiotic susceptibility and acceptable anti-pathogenic activity (Table 1), and was sensitive to all of the seven antibiotics assessed and inhibited growth of all five pathogens assessed. However, the tolerance to high bile salt (53\%) concentrations and low pH (44\%) was poor. Therefore, to compensate for this weakness, the viability of microencapsulation, using differing biopolymer-prebiotic formulations, was evaluated using in-vitro assessment in this study. 
Table 1: Antibiotic susceptibility of isolated E. faecium against the high consumption antibiotics performed by disk diffusion assay and antimicrobial activity of isolate against the pathogenic bacteria

\begin{tabular}{|c|c|c|c|c|c|c|c|}
\hline \multirow[t]{2}{*}{ Strain } & \multicolumn{7}{|c|}{ Antibiotic susceptibility (Clear zone (mm)) } \\
\hline & Oxytetracycline & Tetracycline & Amoxicillin & Ampicillin & Erythromycin & Sulphonamides & $\begin{array}{l}\text { Oxolinic } \\
\text { acid }\end{array}$ \\
\hline $\begin{array}{l}E . \\
\text { faecium }\end{array}$ & 20 & 21 & 23 & 18 & 25 & 16 & 17 \\
\hline \multirow[t]{2}{*}{ Strain } & \multicolumn{7}{|c|}{ Antimicrobial activity (Clear zone $(\mathrm{mm})$ ) } \\
\hline & $\begin{array}{l}\text { Streptococcus } \\
\text { agalactiae }\end{array}$ & \multicolumn{2}{|c|}{ Salmonella enterica } & Streptococcus iniae & Yersinia ruckeri & \multicolumn{2}{|c|}{$\begin{array}{l}\text { Clostridium } \\
\text { botulinum }\end{array}$} \\
\hline $\begin{array}{l}E . \\
\text { faecium }\end{array}$ & 19 & \multicolumn{2}{|l|}{13} & 18 & 13 & \multicolumn{2}{|l|}{14} \\
\hline
\end{tabular}

3.2 Water activity, moisture content, and encapsulation efficiency (EE) of beads

In this study the ALG-PG (F1) and control (ALG) formulations showed the greatest water activity value $(P<0.05)$ compared with the other formulated blends. On the other hand, the water activity values for the ALG-PG + Fk (F5 to F7) formulations were lower than other formulations (Table 2). The moisture content of all the beads prepared in this study was below $3.29 \%(\mathrm{w} / \mathrm{w})$ and there were no differences in the moisture content of the seven gels and control (ALG) formulations in this study, which was in keeping with other researchers who found similarly low water activity and moisture content in the beads that were created during microencapsulation. This low water activity and residual water content has been shown to improve the stability and storage capacity of probiotic-containing beads ${ }^{18}$.

Table 2: Compositions, size, water activity, moisture content (\%), and encapsulation efficiency (\%) of microencapsulated E. faecium with various gel and prebiotic concentrations. Alginate-encapsulated cells $(2 \%(\mathrm{w} / \mathrm{v}))$ were used as control. F1-F7: Various gel formulations. Values shown are means \pm standard deviations $(n=3)$

\begin{tabular}{|c|c|c|c|c|c|c|c|c|}
\hline Formulation & $\begin{array}{l}\text { Alginate } \\
(\% \mathrm{w} / \mathrm{v})\end{array}$ & $\begin{array}{l}P G \\
(\% \mathrm{w} / \mathrm{v})\end{array}$ & $\begin{array}{l}\text { Prebiotic } \\
\text { (FOS) } \\
(\% \mathrm{w} / \mathrm{v})\end{array}$ & $\begin{array}{l}\text { Prebiotic } \\
\text { (Fenugreek) } \\
(\% \mathrm{w} / \mathrm{v})\end{array}$ & $\begin{array}{l}\text { Diameter }(\mu \mathrm{m}) \\
(n=50)\end{array}$ & Water Activity & $\begin{array}{l}\text { Moisture } \\
\text { Content } \\
(\%)\end{array}$ & $\begin{array}{l}\text { Encapsulation Efficiency } \\
(\%)\end{array}$ \\
\hline ALG & 2 & - & - & - & $790-980$ & $0.55 \pm 0.002^{\mathrm{a}^{*}}$ & $3.22 \pm 0.04^{\mathrm{a}^{\star}}$ & $99.1^{a^{*}}$ \\
\hline $\mathrm{F} 1$ & 1.5 & 0.5 & - & - & $320-350$ & $0.48 \pm 0.003^{b}$ & $3.25 \pm 0.06^{a}$ & $98.8^{a}$ \\
\hline $\mathrm{F} 2$ & 1.5 & 0.5 & 1 & - & $360-370$ & $0.37 \pm 0.001^{c}$ & $3.12 \pm 0.03^{a}$ & $99.4^{a}$ \\
\hline F3 & 1.5 & 0.5 & 1.5 & - & $360-380$ & $0.36 \pm 0.004^{c}$ & $3.29 \pm 0.06^{a}$ & $99.6^{a}$ \\
\hline $\mathrm{F} 4$ & 1.5 & 0.5 & 2 & - & $390-410$ & $0.34 \pm 0.005^{c}$ & $2.98 \pm 0.02^{\mathrm{a}}$ & $99.0^{\mathrm{a}}$ \\
\hline F5 & 1.5 & 0.5 & - & 1 & $540-580$ & $0.27 \pm 0.006^{d}$ & $3.18 \pm 0.07^{a}$ & $98.6^{a}$ \\
\hline F6 & 1.5 & 0.5 & - & 1.5 & $570-600$ & $0.25 \pm 0.007^{d}$ & $2.92 \pm 0.05^{\mathrm{a}}$ & $99.3^{a}$ \\
\hline F7 & 1.5 & 0.5 & - & 2 & $640-670$ & $0.24 \pm 0.002^{d}$ & $3.08 \pm 0.08^{a}$ & $99.5^{a}$ \\
\hline
\end{tabular}

*Values followed by the same letters are not significantly different $(P<0.05)$. Statistical analysis of each formulation was done separately.

ALG: alginate-encapsulated cells. PG: Persian gum. FOS: fructooligosaccharides.

In terms of the encapsulation efficiency in this study, there were no difference between the seven gel and ALG as control (Table 2) formulations, all of which showed a high encapsulation efficiency $(>98.6 \%)$ that indicated the successful entrapment of viable probiotic cells within the beads that were prepared, which facilitates the efficient release of viable probiotic cells $(1-2 \times 108 \mathrm{CFU} / \mathrm{g})$ at the required site of impact. Similarly, high rates of encapsulation efficiency, close to $100 \%$, have been reported by other researchers through different encapsulation methods ${ }^{25}$. The results from this study showed that the encapsulation efficiency was independent of formulation, while some sources have reported that the polymer concentration and composition affected encapsulation efficiency 26,27 .

\subsection{Survival rate of E. faecium under fish simulated digestive conditions}

The results from this study show that the un-encapsulated $E$. faecium were highly sensitive to simulated fish digestive conditions and the survival rate and viability were low, changing from an initial cell count of $9.87 \pm 0.02 \mathrm{Log} \mathrm{CFU} / \mathrm{g}$ to $3.85 \pm 0.05 \mathrm{log} \mathrm{CFU} / \mathrm{g}$ following incubation harsh conditions, resulting in a survival rate of approximately $39 \%$ (Table 3 ). This survival rate was similar to results from other studies demonstrating a substantial loss of free probiotics cells in simulated digestion conditions ${ }^{28,29}$. 
Table 3: Survival rates of microencapsulated E. faecium with various gel and prebiotic concentrations after incubation in simulated fish gastric juices $(0.08 \mathrm{M} \mathrm{HCl}$ containing $0.2 \% \mathrm{NaCl}, \mathrm{pH} 1.4)$ for $0,30,60,90$ and $120 \mathrm{~min}$ and sequentially in stimulated fish intestinal juice containing ( $0.5 \%$ w/ $\mathrm{v}$ oxgall, $\mathrm{pH} 8$ at $37^{\circ} \mathrm{C}$ for $\left.120 \mathrm{~min}\right)$. Alginate-encapsulated cells $(2 \%(\mathrm{w} / \mathrm{v}))$ were used as control. F1-F7: various gel formulations. Values shown are means \pm standard deviations $(n=3)$

\begin{tabular}{|c|c|c|c|c|c|c|c|c|}
\hline \multirow[t]{2}{*}{ Formulation } & \multirow[t]{2}{*}{ Prebiotics } & \multirow[t]{2}{*}{ Con. (\%) } & \multicolumn{5}{|c|}{ Mean count of cells after incubation (log CFU/g) } & \multirow[t]{2}{*}{ SR $(\%)$} \\
\hline & & & $0 \mathrm{~min}$ & $30 \mathrm{~min}$ & $60 \mathrm{~min}$ & $90 \mathrm{~min}$ & $120 \mathrm{~min}$ & \\
\hline Un-microencapsulated Cells & - & - & $9.87 \pm 0.02$ & $5.12 \pm 0.04$ & $4.73 \pm 0.05$ & $4.18 \pm 0.01$ & $3.85 \pm 0.05$ & $39^{a^{*}}$ \\
\hline ALG & - & - & $9.76 \pm 0.04$ & $5.04 \pm 0.01$ & $4.77 \pm 0.06$ & $4.59 \pm 0.07$ & $4.39 \pm 0.06$ & $45^{\mathrm{b}}$ \\
\hline $\mathrm{F} 1$ & - & - & $9.69 \pm 0.02$ & $6.23 \pm 0.04$ & $5.94 \pm 0.03$ & $5.46 \pm 0.08$ & $5.14 \pm 0.01$ & $53^{c}$ \\
\hline $\mathrm{F} 2$ & FOS & 1 & $9.92 \pm 0.07$ & $7.18 \pm 0.03$ & $6.74 \pm 0.02$ & $6.51 \pm 0.04$ & $6.05 \pm 0.04$ & $61^{d}$ \\
\hline F3 & FOS & 1.5 & $9.79 \pm 0.03$ & $7.42 \pm 0.01$ & $7.09 \pm 0.09$ & $6.58 \pm 0.04$ & $6.17 \pm 0.03$ & $63^{d}$ \\
\hline $\mathrm{F} 4$ & FOS & 2 & $9.94 \pm 0.04$ & $7.58 \pm 0.03$ & $7.26 \pm 0.02$ & $6.89 \pm 0.07$ & $6.36 \pm 0.02$ & $64^{\mathrm{d}}$ \\
\hline F5 & fenugreek & 1 & $9.57 \pm 0.05$ & $7.97 \pm 0.04$ & $7.56 \pm 0.03$ & $7.36 \pm 0.04$ & $6.99 \pm 0.07$ & $73^{e}$ \\
\hline F6 & fenugreek & 1.5 & $9.91 \pm 0.06$ & $8.12 \pm 0.01$ & $7.91 \pm 0.04$ & $7.74 \pm 0.07$ & $7.43 \pm 0.05$ & $75^{\mathrm{e}}$ \\
\hline F7 & fenugreek & 2 & $9.83 \pm 0.01$ & $8.59 \pm 0.02$ & $8.33 \pm 0.06$ & $8.12 \pm 0.05$ & $7.96 \pm 0.04$ & $81^{f}$ \\
\hline
\end{tabular}

*Values followed by the same letters are not significantly different $(P<0.05)$. Statistical analysis of each formulation was done separately.

ALG: alginate-encapsulated cells. FOS: fructooligosaccharides. Con: Concentration, SR: Survival Rate.

In this study all these seven gel formulations had a greater survival rates than ALG-encapsulated beads (control) following the exposure to simulated fish digestive conditions, however, the highest microencapsulated cell survival rates were observed in the F5, F6, and F7 (Table 3). The E. faecium survival rates in microencapsulated in ALG-PG blend with 1\%, 1.5\%, and 2\% Fk were 73\%, 75\%, and $81 \%$ respectively and the survival rate for ALG-PG blend with $2 \%$ Fk (F7) was the greatest in this study, showing a 1.87 log decrease in the cell CFU counts within the first $2 \mathrm{~h}$ of incubation, while other blends showed a continuous decrease of between 2.48 and $5.37 \mathrm{log}$ in the cell CFU (Table 3). Similarly well protected formulations, with the ability to survive harsh digestive condition, have been reported when psyllium ${ }^{9}$, whey protein ${ }^{30}$ and milk ${ }^{30}$ were incorporation with ALG.

In this study, combining FOS and Fk with ALG-PG mixture resulted in a 22 to $42 \%$ increase in probiotic cell viability, and increasing the prebiotic content from 1 to $2 \%$ increased cell viability even more, possibly due to prebiotics' protective and nutritive functions. Fk, on the other hand, had a stronger beneficial impact in a simulated digestive situation (34-42\%) than FOS (22-25\%). Fk's great protective ability can be attributed to the higher density of beads produced by its robust structure. The binding of glucuronic acid to divalent cations is primarily responsible for the crosslinking of ALG molecules. The stability and permeability of ALG-biopolymer membranes are influenced by their molecular weight and chemical content. As a result, combining ALG with flexible biopolymers like Fk enhances the strength of synthetic blends. The stability of the ALG-biopolymer is determined by the precursor structure, biopolymer molar ratio, and addition sequence ${ }^{31}$.

\subsection{Storage stability of microencapsulated E. faecium in food pellet}

Feed products that can be used as probiotic-carriers, such as pelleted fish feed, are usually stored for six to eight weeks at room temperature ( $\left.25^{\circ} \mathrm{C}\right)$, which has informed storage stability experiments ${ }^{32}$. The free E. faecium cell viability in un-microencapsulated $E$. faecium decreased from 9.73 to 2.87 log CFU/g during the whole seven week storage period, which was greatest during the first week followed by a gentle consistent decline, which was likely to be due to a temperature shock $\left(25^{\circ} \mathrm{C}\right)$ for the cells during the first week, followed by an adaptation process (Fig 1). A similar decrease trend was observed by Haghshenas et al. (2015) ${ }^{11}$, in which the survival rate of free $E$. durans $39^{\circ} \mathrm{C}$ cells and following one month of storage, the cell count in yogurt lowered from 9.52 to $2.83 \log \mathrm{CFU} / \mathrm{g}$.

The results from this study showed that $E$. faecium microencapsulated in ALG (control) and all seven gel formulations had good storage stability, which was similar to other researchers who found that the low temperature storage stability $\left(25^{\circ} \mathrm{C}\right)$ of encapsulated probiotics in ALG-gum Arabic ${ }^{33}$, ALGchitosan (Chavari et al., 2010) and ALG-psyllium ${ }^{9}$. In this study, the ALG-PG (F1) and ALG-PG blended with FOS (F2-F4) showed moderate protection, with a 0.10 to $1.09 \mathrm{log}$ increase in $\mathrm{CFU} / \mathrm{g}$, while an excellent cell survival rate during storage (>115\%) was found when ALG-PG + Fk formulations (F5 to F7) were evaluated. Moreover, the gel formulation formulated with greater Fk concentrations (F7) in this study, showed a greater protective capacity compared to lower Fk concentrations (F5 and F6) (Fig. 1), due to greater Fk (2\%) concentration forming a dense, strong membrane and growth-stimulating activity of Fk, however the extrusion of highly concentrated blends are difficult to press through the nozzle gage, which lowers the encapsulation efficiency.

\subsection{Release assay of microencapsulated E. faecium}


The effective microencapsulated of probiotics into feed is required to have animal health-promoting effects and to achieve the probiotic cells must be released in sufficient quantity and within an appropriate time frame. Thus, the time-dependent release of probiotic cells from the microencapsulation beads within the simulated intestine solution is a critical ${ }^{21}$ and, in this study, an initial number $\left(1 \times 10^{7} \mathrm{CFU} / \mathrm{g}\right)$ of E. faecium was selected for release assay. However, previous researches have indicated that the concentration and composition of polymers used in the microencapsulation process influence the release of cells from the beads ${ }^{34}$. In this study the Log CFU/g, for released E. faecium from ALG blend (control), was stable (7 to 7.2 ) and there were no significant changes in the rate bacterial growth (Fig 2), which was similar to results previously reported by Mandal et al. (2006) ${ }^{21}$ and Nami et al. (2017) ${ }^{33}$ in terms of the sustained and continuous release of cells from ALG.

Once the cell release was complete, in this study, there were significant additive release rates observed from the prepared formulations (F1 to F7), resulting in a greater rate of release due to the growth-stimulating effects of PG, FOS or Fk, and as potential prebiotics, these can release and deliver a greater population of probiotic cells to the active sites in the intestine. In this study, the microencapsulation of E. faecium with ALG-PG or Fk (F5 to F7) was able to release between 33 and $44 \%$ of the beads after one hour of incubation and was fully release after two hours. Log CFU / g for F5, F6, and F7 formulations increased from 7 to 9.9, which was greater than the release rates from the other formulations (7 to 8.1), while greater concentration of Fk (2.0\%) (F7) lowered the rate of probiotic cell release (33\%) within the first hour, however the full release was complete after $2 \mathrm{~h}$ (Fig 2 ), showing how the addition of Fk to the ALG-PG blend lowered the rate of probiotic cell release from the beads. Similar results have been observed previously 7,35 , which were probably due to a more dense membrane on the beads that were covered by the rigid structure of Fk.

In this study the ALG-PG (F1) and ALG-PG + FOS blends (F2-F4) released between 54 and $61 \%$ of the probiotic cells within one hour, while the full release was completed after two hours. The greater early rate of release compared with Fk in this study was probably due to the erosion of loose networks in formulations.

\subsection{Anti-pathogenicity against Streptococcus agalactiae and histopathological assay}

The results from this part of the study highlighted how the different analytical assay of microencapsulated probiotic beads indicated high encapsulation efficiency and acceptable viability of probiotic cells in simulated fish digestive as well as the greater stability of viable cells in all the experimental gel formulations. It also demonstrated that the findings in the in vivo challenge reported in this paper demonstrated that the G05 to $\mathrm{G} 011$ microencapsulated $E$. faecium probiotic formulations could be used to improve the health and viability of tilapia fish infected Streptococcus agalactiae. This research, in this paper, provides a novel investigation of the microencapsulated E. faecium probiotic-supplemented diet and its application in controlling the mortality rate of tilapia fish infected streptococcus agalactiae.

In this study, tilapia fish infected showed hemorrhage and red skin, particularly around the anus and eyes, exophthalmia, cloudy eyes and erratic swimming movement, in addition some hemorrhage and ulceration near the mouth were observed (Fig. 3A and B) and similar clinical signs were observed by other researchers ${ }^{36,37}$. The tissue samples collected from the eye, kidney, liver, brain, spleen, and skin of fish infected and showing clinical signs of Streptococcosis and histopathological changes, which included hemorrhage and congestion of blood vessels in the brain, eye, kidney, liver, and spleen. Melanomacrophage centers (MMCs) in the kidney, liver, and spleen was observed. In the kidney, dissolution, and degeneration of some tubules, necrosis of tubular cells, glomeruli degeneration, attachment to bowman capsule, and congestion of renal vessels were observed. Liver changes included swelling, degeneration, and necrosis of hepatocytes and nuclear pyknosis (Fig. $3 \mathrm{C}$ and E). Also, the organs of the fish in probiotic treated and control group which showed no infection were chosen for histopathology test as normal organs (Fig 3D and F). The observed clinical signs were similar to those in other studies, confirming that the tilapia fish were infected by causative agents of streptococosis (S. agalactiae) ${ }^{38}$. The infected organs also were sampled and after biochemical and molecular identification, it was obtained that the cause of infection was $S$. agalactiae bacteria.

Previous researches have shown that probiotics improved the survival rates of fish to pathogenic Aeromonas hydrophila, Flavobacterium psychrophilum, Streptococcus iniae, Vibrio harveyi, and Pseudomonas fluorescens ${ }^{39-41}$ are some of the strains that have been identified. The survival rates of the treated red hybrid tilapia with free or varied concentrations of probiotic cells (17-63\%) were higher than those of the infected fish that were not treated with probiotics $\left(\mathrm{CON}^{+}\right)(4 \%)$. Furthermore, the ALG-PG $+2 \%$ Fk formulation (F7) had a decent survival rate (63\%) while the control group injected with PBS (CON) had no mortality during the trial period (Table 4). Other researchers found that complex dietary probiotics containing Bacillus and Pediococcus spp. had low anti-pathogenic activity against $S$. agalactiae in red hybrid tilapia ${ }^{42}$; however, according to the findings of this study, probiotic $E$. faecium isolated from ewe colostrum demonstrated excellent resistance to $S$. agalactiae in red hybrid tilapia for the first time. Other studies, on the other hand, demonstrated that B. subtilis-containing diets had no anti-pathogenic activity against streptococcal agents ${ }^{43}$.

Table 4: Mortality and survival rates of fish infected with S. agalactiae $\left(1.6 \times 10^{8} \mathrm{CFU} / \mathrm{mL}\right)$ after 90 days of feeding with food pellets containing $E$. faecium microencapsulated with various gel and prebiotic concentrations. The control group (CON) injected with $0.1 \mathrm{~mL}$ of phosphate-buffered saline (PBS, pH 7.4). $\mathrm{CON}^{+}$group injected with $1.6 \times 10^{8} \mathrm{CFU} / \mathrm{mL}$ of $S$. agalactiae without probiotic treatment. F1-F7: various gel formulations. Values shown are means \pm standard deviations $(n=3)$ 


\begin{tabular}{|lllllllll|}
\hline Formulation & $\begin{array}{l}\text { Alginate } \\
(\% \mathrm{w} / \mathrm{v})\end{array}$ & $\begin{array}{l}\text { PG } \\
(\% \mathrm{w} / \mathrm{v})\end{array}$ & $\begin{array}{l}\text { Prebiotic } \\
(\mathrm{FOS}) \\
(\% \mathrm{w} / \mathrm{v})\end{array}$ & $\begin{array}{l}\text { Prebiotic } \\
(\text { Fenugreek })\end{array}$ & $\begin{array}{l}\text { Probiotic strain } \\
(\% \mathrm{w} / \mathrm{v})\end{array}$ & $\begin{array}{l}\text { Pathogen strain } \\
\text { Fish mortality }\end{array}$ & $\begin{array}{l}\text { survival } \\
\text { rates } \\
(\%)\end{array}$ \\
\hline CON & - & - & - & - & - & - & 0 & $100^{\mathrm{a}^{*}}$ \\
\hline CON+ & - & - & - & - & - & S. agalactiae & $29 / 30$ & $4 \pm 1.15^{\mathrm{b}}$ \\
\hline Free Cell & - & - & - & - & E. faecium & S. agalactiae & $25 / 30$ & $17 \pm 1.25^{\mathrm{c}}$ \\
\hline ALG & 2 & - & - & - & E. faecium & S. agalactiae & $23 / 30$ & $24 \pm 2.0^{\mathrm{d}}$ \\
\hline F1 & 1.5 & 0.5 & - & - & E. faecium & S. agalactiae & $20 / 30$ & $34 \pm 2.20^{\mathrm{e}}$ \\
\hline F2 & 1.5 & 0.5 & 1 & - & E. faecium & S. agalactiae & $18 / 30$ & $40 \pm 1.75^{\mathrm{f}}$ \\
\hline F3 & 1.5 & 0.5 & 1.5 & - & E. faecium & S. agalactiae & $18 / 30$ & $40 \pm 1.55^{\mathrm{f}}$ \\
\hline F4 & 1.5 & 0.5 & 2 & - & E. faecium & S. agalactiae & $17 / 30$ & $43 \pm 1.85^{\mathrm{f}}$ \\
\hline F5 & 1.5 & 0.5 & - & 1 & E. faecium & S. agalactiae & $15 / 30$ & $50 \pm 2.15^{\mathrm{g}}$ \\
\hline F6 & 1.5 & 0.5 & - & 1.5 & E. faecium & S. agalactiae & $15 / 30$ & $50 \pm 2.23^{\mathrm{g}}$ \\
\hline F7 & 1.5 & 0.5 & - & 2 & E. faecium & S. agalactiae & $11 / 30$ & $63 \pm 1.75^{\mathrm{h}}$ \\
\hline
\end{tabular}

*Values followed by the same letters are not significantly different $(P<0.05)$. Statistical analysis of each formulation was done separately.

Free Cell: Un-encapsulated probiotic cells. ALG: alginate-encapsulated probiotic cells. PG: Persian gum. FOS: fructooligosaccharides.

Because probiotics can help fish cope with diseases by increasing their immune systems, these disparities in tilapia fish findings could be related to differences in probiotic strains, culture systems, and treatment methods ${ }^{44}$. The most effective tested formulation in this study for protecting tilapia against the highly pathogenic S. agalactiae was dietary E. faecium encapsulated with ALG-PG + $2 \%$ Fk. Because survival rates did not improve to $100 \%$, more research into $E$. faecium in conjunction with other probiotic strains or in various encapsulation matrixes may be worthwhile. The use of dietary probiotics and continued study in this area are likely to help lower the incidence of harmful bacteria in tilapia aquaculture, allowing for a more ecologically friendly expansion of the tilapia breeding business. The observed results also can highlight in two part. First), different analytical assay of microencapsulated probiotic beads indicated high encapsulation efficiency and acceptable viability of probiotic cells in simulated fish digestive as well as high stability of viable cells in all experimental gel formulations. Second) the finding of in vivo challenge test the present report demonstrates that the G05 to G011 microencapsulated $E$. faecium probiotic treatment could be used for treating infected streptococcus agalactiae tilapia fish. This research represents a novel investigation to use microencapsulated $E$. faecium probiotic-supplemented diet to control mortality rate of infected streptococcus agalactiae tilapia fish. In conclusion, the probiotic $E$. faecium cells were successfully microencapsulated in appropriate sizes and shapes utilizing ALG-PG blends with varied concentrations of FOS and Fk. According to the findings, the ALG-PG + 2 percent Fk (F7) formulation had the highest encapsulation efficiency, viability in gastrointestinal conditions and during storage time, increased cell release, and excellent anti-pathogenicity against $S$. agalactiae. Local herbal gums such as $P G$ and Fk, in combination with ALG, are recommended as a suitable scaffold and an ideal matrix for probiotic encapsulation. As a prebiotic, these herbal gums promote the growth of probiotic cells in the food environment and digestive tract.

\section{Declarations}

\section{Author contributions}

All authors listed have made a substantial, direct, and intellectual contribution to the work, and approved it for publication. AK: designing experiment. YN \& MK: writing. GL: data analysis. MJ: revising. BH: project administrator.

\section{Acknowledgment}

The financial supports of the Kermanshah University of Medical Sciences are gratefully acknowledged.

\section{Funding}

This work was supported by the Deputy for Research and Technology of Kermanshah University of Medical Sciences (Grant No. 990445).

\section{Ethics}

The study involving 'using of microencapsulation technique for lactic acid bacteria by native hydrogels in order to increase the efficiency and durability of probiotic products' was reviewed and approved by Dr. Mahmood Reza Moradi (Chairman of the Academic/Regional Ethics Committee in Biomedical 
Research) and Dr. Farid Najafi (Secretary of the Academic/Regional Ethics Committee in Biomedical Research) of Kermanshah University of Medical Sciences (Approval ID: IR.KUMS.REC.1399.531).

\section{References}

1. Suhermanto, A., Sukenda, S., Zairin Jr, M., Lusiastuti, A. M. \& Nuryati, S. Characterization of Streptococcus agalactiae bacterium isolated from tilapia (Oreochromis niloticus) culture in Indonesia. Aquaculture, Aquarium, Conservation \& Legislation, 12, 756-766 (2019).

2. Huang, L. et al. Construction and characterization of a chimeric lysin ClyV with improved bactericidal activity against Streptococcus agalactiae in vitro and in vivo. Applied microbiology and biotechnology, 104, 1609-1619 (2020).

3. Yuliana, N., Koesoemawardani, D. \& Susilawati, S. Lactic acid bacteria during fish fermentation (rusip). Rusip is one of typical lactic acid fish fermented food originating from Bangka Belitung. To develop this product, the data of lactic acid bacteria involved during fermentation is necessary. This research was aimed at preliminary identifying the lactic, 6, 211-216 (2018).

4. Helmi, A. M. et al. A review of bacterial zoonoses and antimicrobial resistant (AMR) on grouper fish (epinepholus sp.). Sys Rev Pharm 2020; 11 (9): 79 88 (2020).

5. Evans, J. et al. Characterization of $\beta$-haemolytic Group B Streptococcus agalactiae in cultured seabream, Sparus auratus L., and wild mullet, Liza klunzingeri (Day), in Kuwait. Journal of Fish Diseases, 25, 505-513 (2002).

6. Jantrakajorn, S., Maisak, H. \& Wongtavatchai, J. Comprehensive investigation of streptococcosis outbreaks in cultured Nile tilapia, Oreochromis niloticus, and red tilapia, Oreochromis sp., of Thailand. Journal of the world aquaculture society, 45, 392-402 (2014).

7. Haghshenas, B. et al. Microencapsulation of probiotic bacteria L actobacillus plantarum $15 \mathrm{HN}$ using alginate-psyllium-fenugreek polymeric blends. Journal of applied microbiology, 118, 1048-1057 (2015).

8. Rahimi, S. \& Abbasi, S. Fractionation and Determination of Some Structural Properties of Persian Gum. Journal of Food Biosciences and Technology, 8, 81-90 (2018).

9. Chávarri, M. et al. Microencapsulation of a probiotic and prebiotic in alginate-chitosan capsules improves survival in simulated gastro-intestinal conditions. International journal of food microbiology, 142, 185-189 (2010).

10. Mokarram, R., Mortazavi, S., Najafi, M. H. \& Shahidi, F. The influence of multi stage alginate coating on survivability of potential probiotic bacteria in simulated gastric and intestinal juice. Food Res. Int, 42, 1040-1045 (2009).

11. Haghshenas, B. et al. Potentially probiotic acetic acid bacteria isolation and identification from traditional dairies microbiota. International Journal of Food Science \& Technology, 50, 1056-1064 (2015).

12. Nami, Y., Haghshenas, B., Haghshenas, M. \& Yari Khosroushahi, A. Antimicrobial activity and the presence of virulence factors and bacteriocin structural genes in Enterococcus faecium CM33 isolated from ewe colostrum. Frontiers in microbiology, 6, 782 (2015).

13. Manage, P. M. Heavy Use of Antibiotics in Aquaculture; Emerging Human and Animal Health Problems-A review(2018).

14. Nami, Y. et al. Novel autochthonous lactobacilli with probiotic aptitudes as a main starter culture for probiotic fermented milk. LWT, 98, 85-93 (2018).

15. Haghshenas, B. et al. Probiotic assessment of Lactobacillus plantarum $15 \mathrm{HN}$ and Enterococcus mundtii $50 \mathrm{H}$ isolated from traditional dairies microbiota. Advanced pharmaceutical bulletin, 6, 37 (2016).

16. Novoslavskij, A. et al. Major foodborne pathogens in fish and fish products: a review. Annals of microbiology, 66, 1-15 (2016).

17. Simas-Tosin, F. et al. Polysaccharide of nectarine gum exudate: Comparison with that of peach gum. Carbohydr. Polym, 76, 485-487 (2009).

18. Eratte, D. et al. Co-encapsulation and characterisation of omega-3 fatty acids and probiotic bacteria in whey protein isolate-gum Arabic complex coacervates. Journal of functional foods, 19, 882-892 (2015).

19. Fischer, M. H. et al. The gel-forming polysaccharide of psyllium husk (Plantago ovata Forsk). Carbohydrate research, 339, 2009-2017 (2004).

20. Haghshenas, B. et al. Bioactivity characterization of Lactobacillus strains isolated from dairy products. Microbiologyopen, 4, 803-813 (2015).

21. Mandal, S., Puniya, A. \& Singh, K. Effect of alginate concentrations on survival of microencapsulated Lactobacillus casei NCDC-298. Int. Dairy J, 16, 1190-1195 (2006).

22. Ayoola, S., Ajani, E. \& Fashae, O. Effect of probiotics (Lactobacillus and Bifidobacterium) on growth performance and hematological profile of Clarias gariepinus juveniles. World journal of fish and Marine Sciences, 5, 01-08 (2013).

23. Deng, W., Xi, D., Mao, H. \& Wanapat, M. The use of molecular techniques based on ribosomal RNA and DNA for rumen microbial ecosystem studies: a review. Molecular biology reports, 35, 265-274 (2008).

24. Morelli, L. In vitro assessment of probiotic bacteria: from survival to functionality. Int. Dairy J, 17, 1278-1283 (2007).

25. Shi, L. E. et al. Encapsulation of probiotic Lactobacillus bulgaricus in alginate-milk microspheres and evaluation of the survival in simulated gastrointestinal conditions. Journal of Food Engineering, 117, 99-104 (2013).

26. Sandoval-Castilla, O., Lobato-Calleros, C., García-Galindo, H., Alvarez-Ramírez, J. \& Vernon-Carter, E. J. Textural properties of alginate-pectin beads and survivability of entrapped Lb. casei in simulated gastrointestinal conditions and in yoghurt. Food Res. Int, 43, 111-117 (2010).

27. Sultana, K. et al. Encapsulation of probiotic bacteria with alginate-starch and evaluation of survival in simulated gastrointestinal conditions and in yoghurt. International journal of food microbiology, 62, 47-55 (2000).

28. Shi, L. E. et al. Encapsulation of Lactobacillus bulgaricus in carrageenan-locust bean gum coated milk microspheres with double layer structure. LWTFood Science and Technology, 54, 147-151 (2013). 
29. Sohail, A., Turner, M. S., Coombes, A., Bostrom, T. \& Bhandari, B. Survivability of probiotics encapsulated in alginate gel microbeads using a novel impinging aerosols method. International Journal of Food Microbiology, 145, 162-168 (2011).

30. Guerin, D., Vuillemard, J. C. \& Subirade, M. Protection of bifidobacteria encapsulated in polysaccharide-protein gel beads against gastric juice and bile. Journal of food protection, 66, 2076-2084 (2003).

31. Sakai, S., Ono, T., ljima, H. \& Kawakami, K. Permeability of alginate/sol-gel synthesized aminopropyl-silicate/alginate membrane templated by calcium-alginate gel. Journal of membrane science, 205, 183-189 (2002).

32. Ding, W. \& Shah, N. P. Survival of free and microencapsulated probiotic bacteria in orange and apple juices. International Food Research Journal, 15, 219-232 (2008).

33. Nami, Y., Haghshenas, B. \& Yari Khosroushahi, A. Effect of psyllium and gum Arabic biopolymers on the survival rate and storage stability in yogurt of Enterococcus durans IW 3 encapsulated in alginate. Food science \& nutrition, 5, 554-563 (2017).

34. Lotfipour, F., Mirzaeei, S. \& Maghsoodi, M. Preparation and characterization of alginate and psyllium beads containing Lactobacillus acidophilus. The Scientific World Journal2012 (2012).

35. Haghshenas, B. et al. Effect of addition of inulin and fenugreek on the survival of microencapsulated Enterococcus durans $39 \mathrm{C}$ in alginate-psyllium polymeric blends in simulated digestive system and yogurt. Asian Journal of pharmaceutical sciences, 10, 350-361 (2015).

36. Ali, A., Hassan, D., Saleha, A. A., Siti, K. B. \& Milud, A. Streptococcus agalactiae the etiological agent of mass mortality in farmed red tilapia (Oreochromis sp.). Journal of Animal and Veterinary Advances, 9, 2640-2646 (2010).

37. Zamri-Saad, M., Amal, M., Siti-Zahrah, A. \& Zulkafli, A. Control and Prevention of Streptococcosis in Cultured Tilapia in Malaysia: A Review.Pertanika Journal of Tropical Agricultural Science37 (2014).

38. Suwannasang, A., Dangwetngam, M., Issaro, A., Phromkunthong, W. \& Suanyuk, N. Pathological manifestations and immune responses of serotypes la and III Streptococcus agalactiae infections in Nile tilapia (Oreochromis niloticus). Songklanakarin Journal of Science and Technology, 36, 499-506 (2014).

39. Kuebutornye, F. K. et al. Mechanisms and the role of probiotic Bacillus in mitigating fish pathogens in aquaculture.Fish physiology and biochemistry, $1-23(2020)$.

40. Jamal, M. T. et al. Use of Probiotics in Commercially Important Finfish Aquaculture.International Journal of Probiotics \& Prebiotics15 (2020).

41. Sharifuzzaman, S. \& Austin, B. Probiotics for disease control in aquaculture.Diagnosis and control of diseases of fish and shellfish,189-222(2017).

42. Ng, W. K., Kim, Y. C., Romano, N., Koh, C. B. \& Yang, S. Y. Effects of dietary probiotics on the growth and feeding efficiency of red hybrid tilapia, Oreochromis sp., and subsequent resistance to Streptococcus agalactiae. Journal of Applied Aquaculture, 26, 22-31 (2014).

43. Shelby, R. A., Lim, C., Yildirim-Aksoy, M. \& Delaney, M. A. Effects of probiotic diet supplements on disease resistance and immune response of young Nile tilapia, Oreochromis niloticus. Journal of Applied Aquaculture, 18, $23-34$ (2006).

44. Kuebutornye, F. K., Abarike, E. D. \& Lu, Y. A review on the application of Bacillus as probiotics in aquaculture. Fish \& shellfish immunology, 87, 820-828 (2019).

\section{Figures}

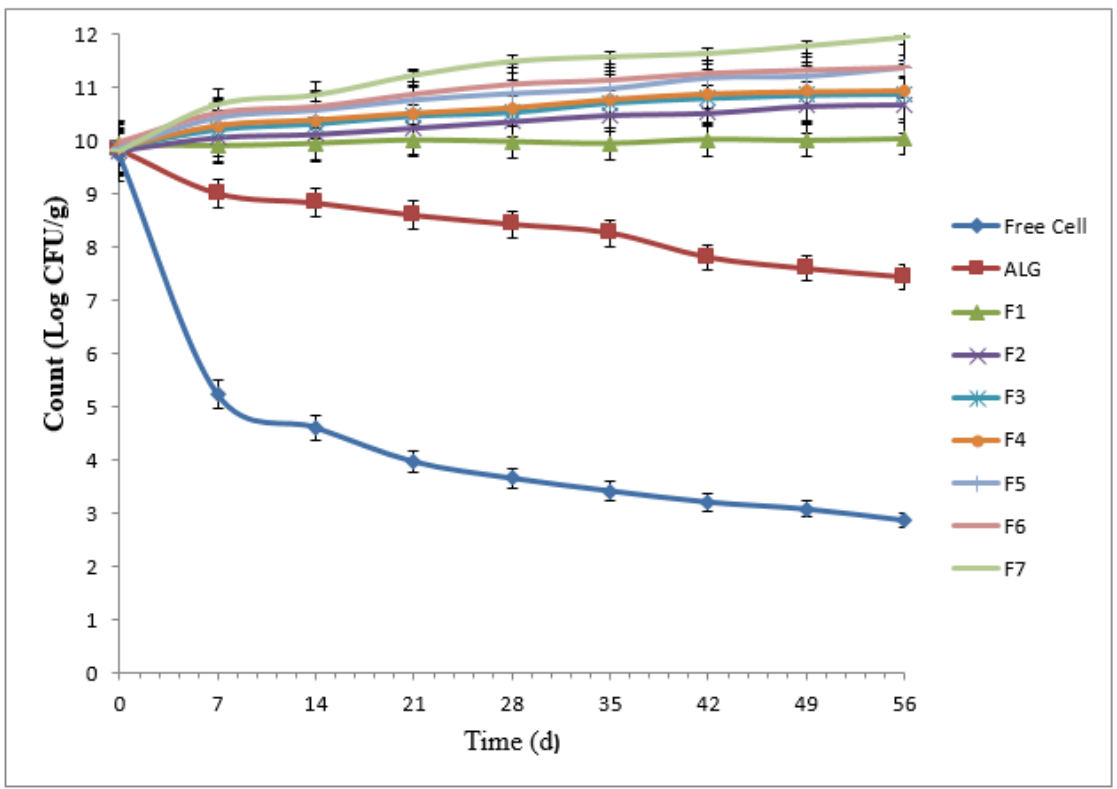

Figure 1 
Number of free and microencapsulated E. faecium with different gel and prebiotic formulations during 8 weeks storage in food pellet at $25^{\circ} \mathrm{C}$. Alginateencapsulated cells $(2 \%(w / v))$ were used as control. F1-F7: various gel formulations. Values shown are means \pm standard deviations $(n=3)$.

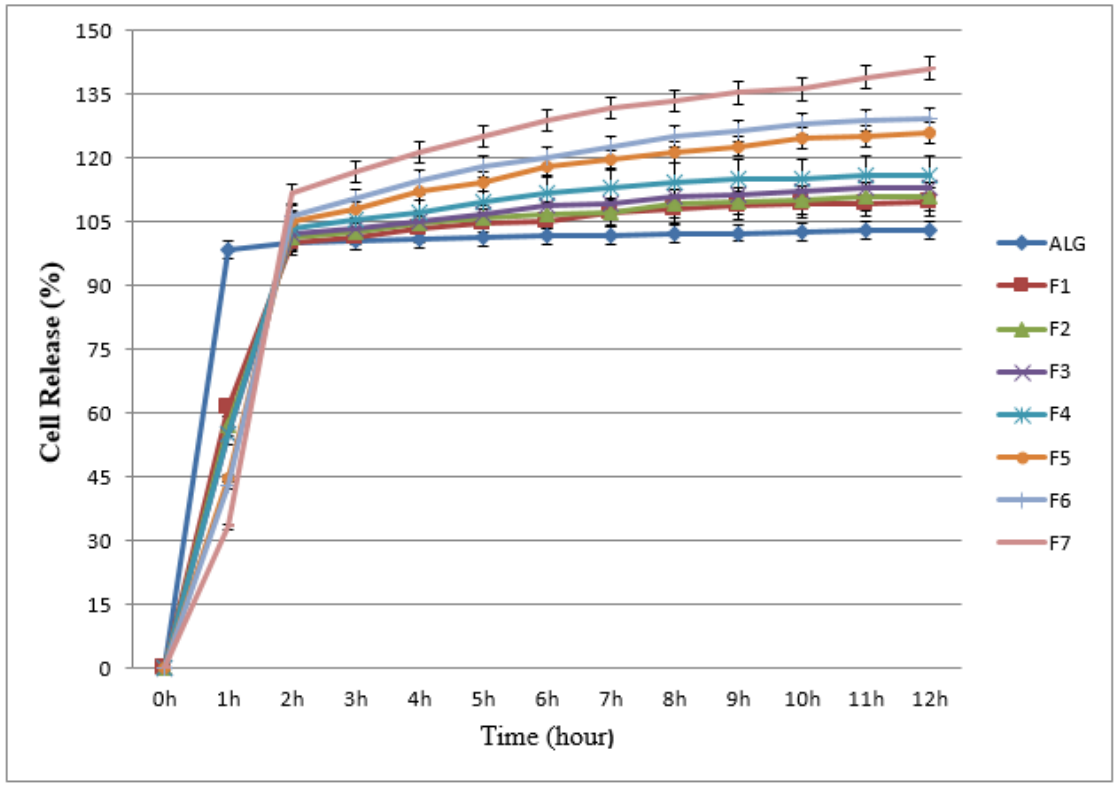

\section{Figure 2}

Releasing rates of microencapsulated $\mathrm{E}$. faecium with different gel formulations at simulated intestine $\mathrm{pH}$ solution containing digestive enzymes in every one $\mathrm{h}$ and for $12 \mathrm{~h}$. ALG: alginate-encapsulated cells (control). F1-F7: Various gel formulations. Values shown are means \pm standard deviations $(\mathrm{n}=3$ ).
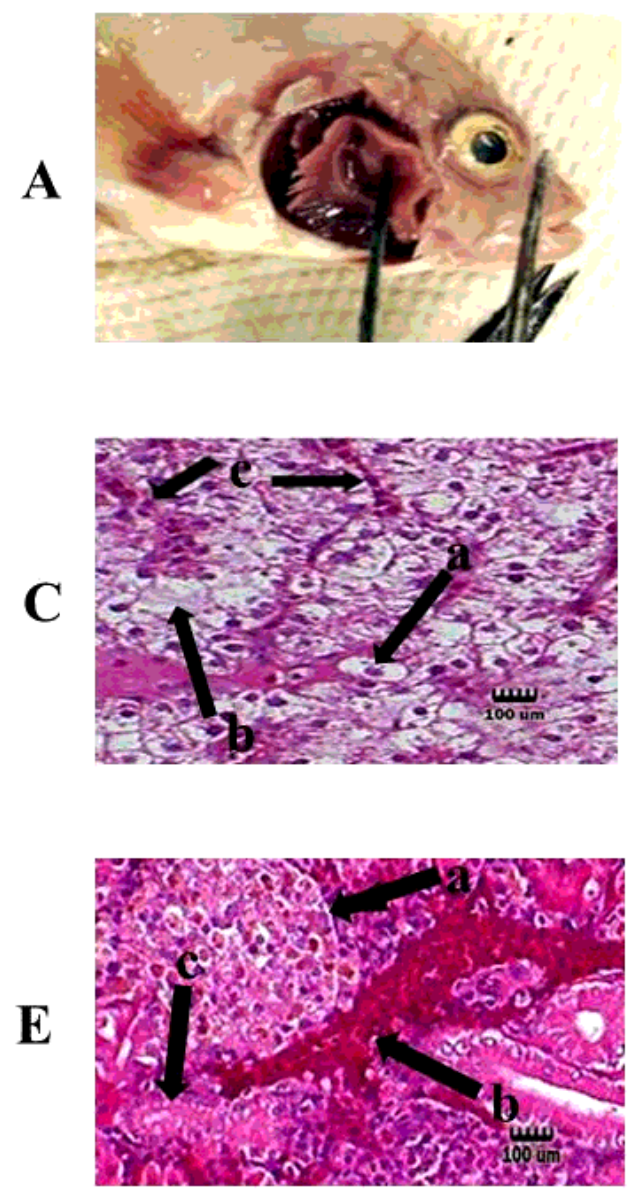
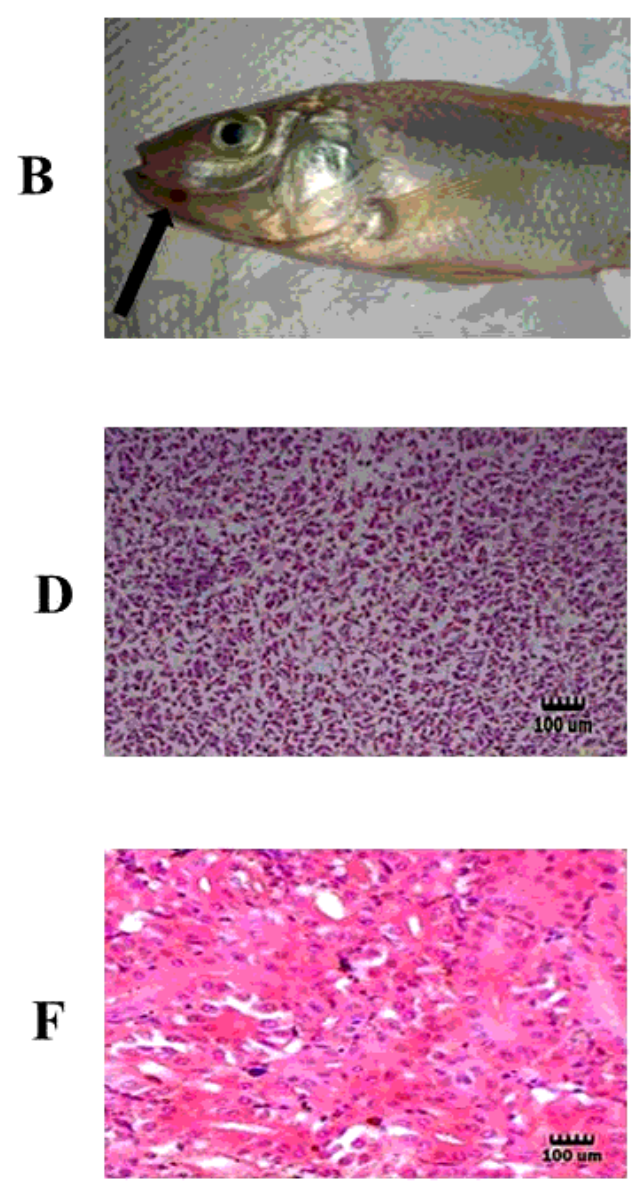

Figure 3 
Hemorrhage on base of the pectoral fin (A) and near the mouth (B) in the infected tilapia (black arrow). Degeneration hepatocytes i.e. swelling (C (a)), necrosis $(C(b))$, and congestion blood vessels $(C(c))$ in the liver of infected tilapia compared with normal liver tissue in probiotic treated group without any infection (D). Presence of corpuscles of stannius (E (a)), congestion in renal vessel (E (b)), and degeneration of tubular cells ( $E(c)$ ) in the kidney of infected fish compared with normal kidney tissue in probiotic treated group without any infection by S. agalactiae (F). H\&E, Mag. 1000x. (Bar=100 $\mu$ m). 